\title{
United in diversity? Analysing behaviour expectations of the European Union as a non-state member of the OECD's development assistance committee
}

\section{Niels Keijzer \& Joren Verschaeve}

To cite this article: Niels Keijzer \& Joren Verschaeve (2018): United in diversity? Analysing behaviour expectations of the European Union as a non-state member of the OECD's development assistance committee, Contemporary Politics

To link to this article: https://doi.org/10.1080/13569775.2018.1432223

\section{Published online: 01 Feb 2018.}

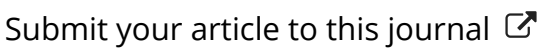

\section{Q View related articles $\square$}

View Crossmark data $\complement$ 


\title{
United in diversity? Analysing behaviour expectations of the European Union as a non-state member of the OECD's development assistance committee
}

\author{
Niels Keijzer ${ }^{\mathrm{a}}$ and Joren Verschaeve ${ }^{\mathrm{b}}$ \\ ${ }^{\mathrm{a}}$ German Development Institute / Deutsches Institut für Entwicklungspolitik (DIE), Bonn, Germany; ${ }^{\mathrm{b}}$ Centre for \\ EU Studies, Ghent University, Ghent, Belgium
}

\begin{abstract}
The European Union (EU) frequently accentuates its position as the largest provider of Official Development Assistance (ODA). Together with the EU institutions, EU Member States represent 21 of the 30 members of the OECD's Development Assistance Committee (DAC) that sets out rules and standards for what can be reported as ODA. Following the EU Treaty's requirement for the EU to work together in international organisations, research has detected a tentative yet positive trend to this end in different international organisations (IOs). This article's empirical analysis shows no such trend can be detected in the EU's engagement in the DAC. Explanatory factors include divergent development cooperation approaches inside the EU, discrepancies between the established image of and everyday practice in the DAC, and the EU's full DAC membership. The findings add to the literature on international organisation governance by exploring different behaviour expectations of non-state membership vis-à-vis that of states.
\end{abstract}

\section{KEYWORDS}

European Union (EU); international organisations; development cooperation; organisation for economic co-operation and development (OECD); development assistance committee (DAC); official development assistance (ODA)

\section{Introduction}

Greater coherence is required between Member States and EU institutions. Coherent and consistent engagement will result in greater credibility, legitimacy, accountability, added value, influence and positive impact on the world. The EU and its Member States must be united in diversity, using a variety of experiences and approaches, bearing in mind their respective comparative advantage. (EU, 2017, p. 5)

The above quote features in the New European Consensus on Development, a detailed and ambitious high-level political statement adopted in June 2017 by the EU and its member states. It is the second such statement adopted in the history of the EU development policy, which finds its origin in its founding Rome Treaty of 1957. Throughout its history, member states remained reluctant to accept further European integration in this area of public policy (Orbie \& Lightfoot, 2017), yet the period between 2000 and 2006 saw various initiatives to promote a common European vision on development. In addition to promoting convergence of and influence on the substance of European 
development policy, the EU institutions also accentuated their ambition to promote coordinated action by the EU and its member states. ${ }^{1}$

During the present decade, the EU's efforts to ensure consistency and concerted action throughout its external policies continue, propelled by the Treaty for the EU that entered into force in 2009 and the subsequent creation of the post of Union High-Representative on Foreign and Security Policy and the European External Action Service (EEAS). These trends have not gone unnoticed in academic circles, as shown by a growing body of work focused on assessing the EU's ambition to promote a common agenda on development. These studies address various aspects, including enabling and constraining factors for EU donor coordination (Carbone, 2013; Delputte \& Orbie, 2014), the Europeanisation of national development policies and ODA budgets (Delputte, Orbie, Lannoo, \& Verschaeve, 2016; Lightfoot \& Szent-Iványi, 2014) or joint EU actions on specific issues and topics such as policy coherence for development, aid for trade or aid effectiveness (Carbone $\&$ Keijzer, 2016; Holden, 2014; Lightfoot \& Kim, 2017).

This study adds to the literature by analysing EU dynamics within the OECD's Development Assistance Committee, a key setting for determining norms for development cooperation that has remained underexplored in EU studies. Although the OECD is omnipresent in academic scholarship on global governance, it is very rarely the object of development policy scholarship. Instead, the literature tends to treat the OECD in a crude manner, typically involving clichés such as 'rich countries club', more often than not involving misrepresentations of the Organisation and how it works (Carroll \& Kellow, 2011; Woodward, 2009). ${ }^{2}$ As per its focus, the present study not only complements the specific field of EU development studies, but also adds to the growing literature on EU actions with (in) international organisations (IOs) (e.g. Hoffmeister, 2007; Jørgensen, 2009; Kaddous, 2015).

The EU and its member states play an active role in numerous IOs, each of which may fulfil a manifold of functions such as facilitating the negotiation of agreements, overseeing or contributing to the implementation of these, managing conflict and mediation, or shaping international policy discourse and norms (Abbott \& Snidal, 1998). The academic literature suggests that the relationship between IOs and their membership is mutually constitutive: members arrange the rules with which IOs function, while in the process the members develop their own appreciations as to what constitutes appropriate behaviour and engagement. Whereas in earlier decades researchers applied either rationalist or constructivist perspectives on agency (Hofferberth, Brühl, Burkart, Fey, \& Peltner, 2011), recent research suggests that the behaviour of the IO itself and its membership can be explained by a 'blend' of norm-based considerations ('culture') and expected consequences ('calculus') (Gavas \& Maxwell, 2017). This dynamic conceptualisation of the relation between IOs and their membership responds to earlier liberal-intergovernmentalist and realist interpretations that treat IOs as passive vessels through which members interact (Moravcsik, 1993).

Recent research further goes beyond a dichotomous understanding whereby 10 autonomy goes at the expense of that of its membership, and instead describes how IOs enter into informal coalitions with some of its membership to further specific aims (Dijkstra, 2017). In the case of the DAC's mandate, namely the production of norms and standards on development cooperation and its measure of ODA, it is assumed that it is both case- and member-dependent as to what measure of culture 
and calculus may explains for their engagement with the secretariat and fellow members. It may further be expected that, in order to be seen as legitimate in their commitment to the DAC, their actions should be seen as adequately contributing to its public goods, while in the process the members also pursue their own interest. An open question is to what extent the EU, as the only 'non-state actor' that is a full member in the DAC, has to meet different expectations as to the acceptable balance between culture and calculus. Beyond the specific topic of this paper, the analysis informs future research inquiry on the engagement and behaviour expectations of non-state members in IOs and thus complement a body of literature that remains strongly focused on statist actors.

The pertinence of the DAC as a case to analyse action by the EU and its Members is threefold. First, the EU and its Member States have a long-standing tradition of coordination on ODA, going back to the Union's collective $0.7 \%$ ODA/GNI target which was adopted in the run up to the UN Monterrey conference in 2002 (Delputte et al., 2016). Second, the EU has increasingly come to prioritise coordinated action at the multilateral level, especially from the mid-2000s onwards (Jørgensen, 2009; Orsini, 2016). Third and final, the EU holds a strong position in the DAC, given that the EU always has been a full member of the Committee alongside the other EU Member States, while collectively also accounting for 21 of the Committee's 30 members (Verschaeve \& Orbie, 2016). It thus constitutes a rare case where the EU's interaction as a member can be analysed vis-à-vis other states that are a member of the DAC. While the Commission asserts that it is 'a member in the same way as 20 EU member states are members' (Prada, 2017), this research analysed to what extent the EU's membership is accompanied by different expectations of behaviour, as informed by the pursuit of common norms as well as own interests, compared to the other DAC members.

The analysis presented in this paper is informed by (i) 15 semi-structured expert interviews with DAC member representatives and OECD officials, ${ }^{3}$ the main points of which were captured by means of written notes; (ii) a structured review of academic and policy documents in relation to the EU and OECD/DAC; and (iii) authors' direct observations of relevant processes and meetings. ${ }^{4}$ The use of these three sources of information allow for presenting a detailed and reliable account of EU dynamics in the DAC, which particularly focused on two specific cases: (i) aid and development effectiveness (mainly 2003-2011) and (ii) ODA reporting system (mainly 2011-date). Whereas the first topic relates to the period in which the EU's federative ambition increased and concerned the effectiveness of development cooperation, the second topic was taken forward in a period when the EU's ambition declined and related mainly to the quality of ODA reporting.

The remainder of this article is structured as follows. First, we provide a general overview of EU development policy, paying particular attention to recent evolutions that are relevant for both the substance and form of EU action in the DAC. Section two provides a general overview of the OECD and its DAC, focusing on their functioning and role in global governance, followed by section three which outlines the EU's particular status and involvement in the OECD/DAC. Finally, section four presents the main findings on the EU's role in the DAC, followed by a concluding section where general reflections are presented in relation to the EU in the DAC. 


\section{Ambitions for and realities of EU coordination}

In recent years the EU has increased its ambition in seeking to promote a common European vision on development and facilitate EU collective action to pursue this vision. This evolution is remarkable, knowing that most EU Members States have always been very reluctant to integrate in the field of development cooperation. Indeed, from the outset of European integration, EU Member States established and consolidated very different development models and systems, tailor-made to their specific national interests (Holland \& Doidge, 2012). For most of its existence the EU Treaties did not include a formal legal competence for the European Union in the field of development policy, which was only realised through the adoption of the Treaty of Maastricht in 1992. This Treaty enshrined development policy as a shared competence of the EU and its member states (Orbie \& Lightfoot, 2017).

In contrast to the strong resistance to EU integration in development policy during the Union's formative decades, the period from 2000 to 2010 saw a proliferation of collective EU statements and targets on a variety of issues and events, ranging from aid effectiveness $(2005,2007,2009)$ to financing for development (2005) and policy coherence for development (2005). Common in these statements is that the EU increasingly assumed a coordinating role in development cooperation. This shift was noteworthy in that previous attempts were unsuccessful due to opposing member states' interests and views on development (Grilli, 1993). Most prominent among these statements was the European Consensus on Development in 2005, which for the first time-ever outlined a common European vision on development policy (Carbone, 2007; Holland \& Doidge, 2012). Signed by the Presidents of the Council, Commission and Parliament, this joint statement prominently stated that 'The EU provides over half of the world's aid and has committed to increase this assistance, together with its quality and effectiveness' (EU, 2006, p. 9). ${ }^{5}$ The statement emphasises norm-based considerations and reflected the EU's ambition to promote the quality and effectiveness of ODA.

Several of the initiatives launched or otherwise supported through the Consensus with a view of strengthening EU coordination continue until today. Cases in points are the EU's Joint Programming Initiative and the common European positions and contributions to the UN 2030 process in Addis (2015) and New York (2015). A New European Consensus for Development was adopted in 2017 to reiterate the Union's ambition to act united and reflects its conviction that consistent and coherent action provides for 'greater credibility, legitimacy, accountability, added value, influence and positive impact' (EU, 2017, p. 6). It is noteworthy that it is the first such statement adopted after the so-called 'big bang enlargement' of 2004 and conveys the commitment of all 28 EU Member States to work together. Yet, as noted in this article's opening quote, this is accompanied by considerable tentative language, including references to 'unity in diversity' and 'respective comparative advantage' without specifying what these comparative advantages concern (Ibid., p. 4). In contrast to its predecessor, the 2017 statement puts forward an ambition for the EU's engagement in development cooperation, but not towards the system as a whole.

Parallel to the emphasis on increasing policy convergence and coordinated action in the development realm, the EU also experienced in the same period a more general move towards increased collective action in its external actions. Indeed, largely triggered by the lack of European unity in response to the Iraq invasion and a more general feeling 
that the EU punched below its weight at the international level, EU institutions and Member States came to realise the need for improving coordinated action. This informed informing relevant provisions in the Treaty on European Union (also referred to as 'Lisbon Treaty') that entered into force in 2009 and to the subsequent establishment of the EEAS. In doing so, a lot of attention was devoted to strengthening the EU's position in IOs (Jørgensen, 2009; Kaddous, 2015; Orsini, 2016). To this end, the Treaty granted the EU legal personality - facilitating its full membership of IOs - as well as introduced the legal obligation to its Members to 'coordinate their action in international organisations and at international conferences' (art 43(1)). This included many IOs with a mandate relating to development policy (e.g. UN, FAO, IMF, WB, OECD) in which the EU plays an active role (Farrell, 2012; Lightfoot \& Kim, 2017).

In sum, from the 2000s onwards, the EU witnessed a remarkable shift towards increased coordination, both in general and in the field of development cooperation. It can be assumed that the EU has both a strong potential and ambition for coordinated action in the DAC, also given the early backing from EU heads of state to a collective effort to provide ODA in 2001 (see European Council, 2001). Despite the Union's ambition, its collective $0.7 \%$ ODA/GNI target was not reached. The EU subsequently moved the deadline for doing so from 2015 to 2030, which raised questions about its own commitment to the policy positions that it advances internationally (Delputte et al., 2016). Studies into other aspects of EU development cooperation, for example the use of budget support (e.g. Koch \& Molenaers, 2016), as well as the EU's involvement in IOs more generally (e.g. Kaddous, 2015) similarly question the Union's abilities and willingness to translate lofty ambitions into effective coordinated action. The literature thus confirms the potential for EU coordinated action in development policy, yet suggests that the EU and its member states are not sufficiently willing and able to do so. The factors to explain this gap between intentions and practice need to be explored further, and the DAC provides a pertinent arena for doing so.

\section{The DAC: an OECD within the OECD}

The OECD holds a unique position in global governance, with its founding convention stating that the OECD was founded to 'promote policies that will improve the economic and social well-being of people around the world' (OECD, 1960). Unlike other IOs, the OECD has no universal membership and instead represents a group of 35 fairly similar and likeminded countries. ${ }^{6}$ By repeatedly bringing together policy makers and experts from these countries on various socio-economic issues, the OECD seeks to foster consensus on matters of national interests - for example through the adoption of shared policy standards and principles. As Woodward (2009, p. 8) puts it, the OECD serves 'primarily as a forum for consultation, where states seek informal consensus on matters of mutual interest, rather than negotiation, where they seek formal rules or legal covenants to govern their behavior.' Once such consensus exists on a specific issue, the OECD typically tries to promote its standards to the rest of the international community (Carroll \& Kellow, 2011).

Further to its mandate, membership and working methods, the OECD also differs from other IOs in terms of its high degree of decentralisation and flexibility. This is facilitated by its broad and open-ended mandate that allows the OECD to initiate work on virtually all socio-economic issues. These issues are discussed and taken further in dedicated 
committees, working groups or other subsidiary bodies: more than 250 at the time of writing. These typically have their own distinctive characteristics in terms of membership, working pace, decision-making culture or even ideological views. A number of them even enjoy a (semi-)autonomous status. Most notably in this regard is the International Energy Agency which is an $\mathrm{IO}$ in its own right, though established and operating within the OECD structures (Carroll \& Kellow, 2011). Importantly, these committees and subsidiary bodies constitute the centre of gravity of the OECD's work as this is the place where Member States' policy makers and experts meet on a regular basis. Hence, many of these committees turn into so-called 'communities of influence' in their respective policy area (Marcussen \& Trondal, 2011; Woodward, 2009). In terms of its approach to decision-making, the OECD operates on a purely intergovernmental basis. Its founding convention describes how decisions may be adopted through voting (OECD, 1960), though, voting seldom takes place in the OECD. ${ }^{7}$ Rather, there is a strong tradition of deliberation and consensus building in Paris, typically reached after a dynamic interaction between the OECD membership and the OECD's Secretariat (Scott \& Ahmad, 2011).

The DAC operates in a similar way as other committees of the OECD, yet for historical reasons enjoys a special position within the Organisation. Initially established in 1959 as an independent IO under the name 'Development Assistance Group' with the aim of coordinating Western development assistance towards former colonies, the DAC became a part of the OECD once the latter had become fully operational in 1961 (Griffiths, 1997; Verschaeve \& Orbie, 2016). Its unique status within the OECD is shown by its own (more strict) membership criteria, a residential chair largely autonomous from the OECD Council, ${ }^{9}$ more frequent meetings at the Committee Delegate level compared to other Committees and a partly independent budget that compared to other Committees relies more on voluntary financial contributions. Therefore, many consider the DAC to be a kind of OECD within the OECD (Verschaeve \& Takacs, 2013).

The DAC's mission is to contribute to increasing both the volume and effectiveness of development finance, with Scott (2015) noting that during its first formative years the Committee deliberately sought to soften the terms under which such finance is provided. The DAC serves as a forum for its members to coordinate their aid activities and establish new development concepts. The DAC's long-term agenda is set out by the membership through high-Level ministerial meetings (HLMs), which are prepared by Senior Level Meetings (SLMs) and the DAC meetings that are attended by mostly Paris-based diplomats. ${ }^{10}$ These are in turn informed by various subsidiary bodies, of which the most well-known one concerns the Working Party on Statistics (WP-STAT) that both prepares and operationalises higher-level decisions on ODA reporting.

While best known for the annual figures on ODA that it adopts, the DAC has also had an important normative role in promoting principles for effective development cooperation. For example, over the past six decades, the DAC has pioneered important development concepts such as (un)tied aid, donor coordination, alignment and policy coherence for development (Verschaeve \& Orbie, 2017). In addition, the DAC also serves as a policy evaluator for its members, conducting periodic peer reviews of their development programmes in order to identify best practices as well as areas where improvements can be made (Ashoff, 2013). The form and culture of the DAC presents a genuine challenge to the EU and its treaty-based ambition to work together in international organisations. 


\section{The EU \& the OECD}

The EU's participation in the OECD is provided under article 13 of the OECD's founding convention, which stipulates that European Commission is guaranteed to take part in all meetings of the organisation's bodies as a full observer (Hadzhieva, 2015; OECD, 1960). The EU also enjoys full membership in a number of OECD committees and subsidiary bodies, including the Steel Committee, the Chemicals Committee, Working Party 3 of the Economic Policy Committee and the DAC (Hadzhieva, 2015; Verschaeve \& Takacs, 2013). With regard to the DAC, Hoffmeister (2007, p. 49) emphasises that 'The Commission may even exercise a right to vote in the OECD development committee, where the Community acts as an additional donor of development aid backed by an independent Community budget.' This understanding was recently confirmed in an exchange of views with the European Parliament (EP), where the Commission representative noted that the Commission was a member in the same way as the $20 \mathrm{EU}$ member states are a member of the DAC (Prada, 2017).

These exceptions of OECD Committees where the EU enjoys full membership stem from historical accidents (in the case of the DAC) or relate to intra-EU divisions of power at the time of the establishment of these bodies. An example of the latter is that the full membership of the Steel Committee was supported by the competences of European Coal and Steel Community. In practice, however, these legal exceptions are easily overlooked, in the sense that the EU is generally perceived as a 'quasi-member' (Woodward, 2009, p. 46) or 'de-facto member' (Debaere, De Ville, Orbie, Saenen, \& Verschaeve, 2016, p. 39) of the OECD at large. This stems from the fact that the EU's participation in the work of the OECD goes well beyond that of a typical (full) observer as the EU actively takes part in the work of all $250+$ committees and subsidiary bodies of the OECD. Although it differs from the full (governmental) OECD members by not voting on legislative matters in the OECD Council and by not contributing to the OECD's core budget, it offsets the latter by providing considerable amounts of voluntary contributions (Hadzhieva, 2015; Verschaeve \& Takacs, 2013).

The EU thus holds a very strong membership status in the OECD, clearly exceeding the observer status it enjoys in most other IOs (Debaere et al., 2016). A similar picture emerges when looking at the EU's collective weight in the OECD, given that the Union today accounts for 21 of the 35 members of the Organisation and even 21 out of 30 in the case of the DAC. This strong (over)representation is mainly due to historical reasons: the OECD emerged from the Organisation for European Economic Cooperation (OEEC), which was the first European integration project after WWII. Hence, there has been a clear European bias from the start which only strengthened over time due to enlargement dynamics of both the EU and OECD, most notably towards Central and Eastern Europe. It should be noted that the EU's collective weight in the DAC is disproportional to its collective ODA share, since many of the new EU DAC members have small bilateral programmes. In such a setting, a practice in which the EU and its member states would enter into 'caucusing' to push particular views is unlikely to be appreciated by non-EU members, since in a way the Union 'programmed' this majority through its enlargement process.

Finally, it is worth pointing out that the EU plays a facilitating role in the DAC. Like all DAC members, the EU makes voluntary contributions as well as offers human resources, in the EU's case principally by - at the period of writing - providing both a DAC vice-chair and 
the chair of WP-STAT. Interviewees however pointed out that this was mostly due to available opportunities as well as the interests and personalities of the people involved, and was not guided by a larger strategy of the EU for its engagement in the DAC. ${ }^{11}$ The EU is well-placed to provide such contributions in that it has more human resources available to engage in the DAC compared to EU member states with small bilateral cooperation portfolios. These human resource contributions are regarded positively as reflecting the EU's commitment to the DAC's mandate and objectives.

\section{The EU's engagement in the DAC: five factors explaining reduced EU coordinated action}

Taking the unique context of the DAC and the EU's membership as described above, the research set out to further look into the engagement of the EU and its Member States in this IO. A starting assumption, as confirmed by earlier research on the history of the EU's full membership (Verschaeve \& Orbie, 2016), is that the EU's membership of the DAC is accompanied by different expectations of behaviour compared to the rest of the DAC's membership. In order to further analyse the mix of pursuit of common norms as well as own interests as guiding the dynamics concerned, we focused on two policy processes which dominated the DAC's works during the period under study, respectively, (i) aid and development effectiveness (2003-2011) and (ii) ODA reporting system regulations (2011 - today).

The main finding of this study is that EU coordinated action in the DAC reached its peak in the mid-2000s and has since declined. This evolution is visualised in Figure 1, which serves as a heuristic tool, indicating the general trends that assist the reader in forming its appreciation of the specific findings set out below. The qualitative representation summarises and visualises the interview findings on differences between the EU's engagement in the DAC in the two different periods.

\section{Prominence in the DAC's work}

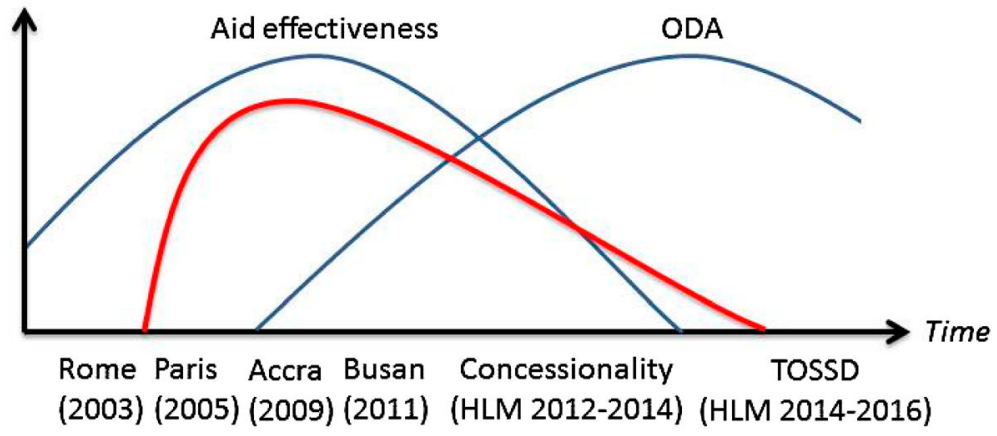

$$
=\text { EU coordinated action }
$$

*Conceptual representation based on interview findings and document analysis

Figure 1. Visualising EU dynamics in relation to two key DAC policy processes*. 
As Figure 1 visualises, EU coordinated action in the work of the DAC reached its peak in the context of the High-Level Forums (HLF) on Aid Effectiveness in Paris (2005), Accra (2009) and Busan (2011). As is detailed below, the EU's joint efforts in this context were prepared both in Paris and Brussels, with an important role for the latter played by socalled 'technical seminars' convened by the EU. ${ }^{12}$ More recently, however, interviewees pointed out that EU coordinated action has diminished, notwithstanding (i) the fact that the main focus of the DAC's work today is on ODA reporting system regulations - a central topic in EU development policy - and (ii) the general move towards improved coordination in the EU's external policies during this period as reinforced by Treaty changes and institutional reform. Five key factors were identified that explain these dynamics and are discussed in turn.

A first explanatory factor concerns the political economy of EU development cooperation approaches. As per its founding mandate, the DAC seeks to transcend its members' interests in providing aid and instead produce and promote norms that enable the community of development cooperation to increase collective effectiveness by means of various soft process of peer review and accountability. While participation in the DAC enables the development of these norms, its membership's engagement is also informed by a logic of expected consequences. Collective agreements thus have to mediate these individual interests and, for instance in the case of a change to the ODA reporting system, avoid providing an advantage to some members over others. Interests convergence would thus enable consensus building among the DAC's membership to further the Committee's aims, in which the EU could play a key role in view of its critical mass. EU Member States have established their own development cooperation approaches in different ways, in response to various factors including needs, history and associated geographic preferences, and various organised interest groups. This resulted in a variety of institutional set-ups and development practices across Europe, which can be characterised as follows: ${ }^{13}$

- Those that mainly disburse via the bilateral channel (EU15) versus those that mainly disburse via the EU and have smaller bilateral portfolios (EU13)

- Those with a strong performance towards or beyond the $0.7 \%$ target (of which two G20 members and smaller EU member states), vis-à-vis those that are far away from it and do not have a strong ambition to meet it soon (most others)

- Those with strict legal requirements as to how ODA should be allocated and reported, and those that are more flexible in this regard.

- Those that spend a high proportion of bilateral ODA on in-donor refugee costs (most EU15, including the high performers), versus those that do not (most EU13, LU, EU)

- Related to the previous characteristic, those with the majority of the bilateral portfolio targeting LDCs versus those with a portfolio emphasising MICs.

- Those with a single ministry (or even cabinet member) in charge of development policy, versus those where the ODA budget is administered by a host of government departments (a rather dynamic characteristic)

- Those that have large Development Finance Institutions of their own, or an own bank with an external investment mandate (DE, FR, UK, EU, NL, BE), versus those that do not and therefore have bilateral portfolios mainly consisting of grants (everyone else) 
- Those that have their own technical cooperation or general implementing organisation (DE, FR, BE, LU, IT, ES) versus those that do not and tend to 'outsource' to the market or NGOs (the rest)

From the viewpoint of discussions within the DAC, these differences differ in terms of hardness. Those that concern (under-)performance may be addressed by sufficient levels of political will, democratic support and fiscal space. Those that relate to the shape of the system used, such as the presence of implementing agencies or development banks, in contrast provide a strong source of path dependency and institutional interests, interests which those same agencies would tend to articulate effectively (Faust \& Messner, 2007). The engagement in the DAC of the latter group of members is commonly associated with a stronger focus on expected consequences, as required by the direct institutional interests that they represent, whereas the former group is assumed to have a stronger focus on appropriateness in relation to the DAC's stated purpose and mandate.

Taking a closer look at both cases, the political economy of EU member states development policy has a strong impact on the potential for EU coordinated action. More specifically, the first case - i.e. aid and development effectiveness (2003-2011) - had little direct impact on the institutional set-up and practices of the EU institutions and member states. Taking the example of the Paris Declaration on Aid Effectiveness (2005), the principles being put forward - i.e. ownership, alignment, harmonisation, results and mutual accountability - have in common that they seek to achieve better aid, without substantially altering the institutional set-up of donor countries. Hence, from a logic of expected consequences, EU institutions and Member States had little to lose or gain, both in general and in relative terms (i.e. all EU actors were equally affected). As a result, there was ample space for coordinated action on the basis of appropriateness concerns, as the decisions and associated peer pressure processes were seen as adding positively to the legitimacy of the DAC and its membership. This reflects, for example, from the EU's joint positions that were adopted before each HLF, as they had in common to be ambitious, striving to establish higher international standards on aid and development effectiveness.

A very different picture emerges from the second case - i.e. ODA reforms (2011 today). More specifically, in the light of the changing nature of the debate on financing for development, the DAC has made a series of ministerial decisions in 2014, 2016 and 2017 that introduced reforms to the ODA reporting system. These reforms addressed issues such as if and how loans and public-private financing modalities should be counted as ODA, the extent to which in-donor refugee costs should be added to a country's aid figures; or the graduation of certain developing countries from the ODA eligible list (Roodman, 2015). The reforms considered would all affect the EU institutions and member states in different ways, depending on their particular institutional set-up and practices. Hence, there was little possibility for EU coordinated action on ODA related topics since decisions in the DAC play out very differently from a logic of expected consequences, always creating 'winners' and 'losers' among the EU actors. Related, and in contrast to the aid effectiveness case, the ODA reporting reforms were mainly regarded from a 'damage control' perspective, in that absence of reform was considered a threat to the DAC's legitimacy. 
A second explanatory factor that attributes to the above evolution (cf. Figure 1) is the changing nature of the DAC, altering the context in which coordinated action can be pursued by the EU and its Member States. Indeed, over the last 14 years, the DAC has been a dynamic body, as can be witnessed by its growing membership (from 23 members in 2003-30 members today) and key evolutions in its subsidiary bodies. These subsidiary bodies inform the DAC's deliberations and comprise working parties, networks on issues such as gender and governance, and the annual Global Forum.

Of particular relevance to this study are the DAC's subsidiary bodies on (i) aid and development effectiveness - i.e. the Working Party on Aid Effectiveness (WP-EFF) and (ii) development financing - i.e. the WP on Development Finance Statistics (WP-STAT), respectively, dealing with the first and second case. Starting with the former, the WP-EFF was created in 2003 as one of the outcomes of the 1st HLF on Aid Effectiveness in Rome. It was host to several thematic clusters and joint ventures which informed the WP's deliberation and subsequent HLFs in Paris (2005), Accra (2009) and Busan (2011) (De Milly, 2012). Following the Busan HLF, the WP-EFF was abolished in 2012 due to the creation of the Global Partnership for Effective Development Cooperation (GPEDC), an international forum to discuss issues related to development effectiveness supported by a joint OECD-UNDP secretariat. In contrast, the WP-STAT has always been a subsidiary body of the DAC, under various names and institutional configurations, determining which expenditures are 'ODA eligible' (Scott \& Ahmad, 2011).

Partly because many DAC officials would travel to Paris for dedicated meetings, there is limited interaction between representatives of WP-STAT and WP-EFF. ${ }^{14}$ WP-EFF provided a forum to pursue coordinated EU positions, while the WP-STAT did not, which interviewees linked to the rather different subject matter and scope of the topics discussed. ${ }^{15}$ Whereas WP-EFF essentially discussed the substance and implementation of development policy, seeking reform through peer pressure while leaving space for diversity, WP-STAT's focus on determining ODA-eligible expenditure is more 'one size fits all' by nature and thus closer to the DAC members' institutional interests. This meant that it was more straightforward for the Commission to play a facilitating role in the WP-EFF, given that the latter's work was less directly related to the individual donor interests of the EU Member States. A central example of joint EU engagement in the DAC concerned the negotiations of the outcome document of the 2nd HLF in 2005.

Two reasons explain the EU's resolve and its effectiveness: first of all, in the year before an EU Ad-hoc Working Group on Aid Harmonisation was prepared and welcomed by the General Affairs and External Relations Council. This document offered considerable detail and operational proposals as to how to increase EU aid effectiveness (Ad-hoc WG, 2004). Secondly, the so-called Nordic+ group of Paris-based DAC representatives had developed proposals and ideas in preceding years in areas such as joint programming, budget support and sector approaches. During the negotiations of the Paris HLF outcome document, circumstances were such that the Commission suggested to the Nordic+ to develop an EU position on the spot. ${ }^{16}$ The Ad-hoc WG report was taken as a key input for the position, which during the forum itself was presented by the rotating EU Presidency Luxemburg, who started his intervention by noting that 'I have the honour to speak on behalf of the European Union' (Schilz, 2005).

The transformation of the WP-EFF into the non-DAC based GPEDC had the unintended effect of changing the substance to be addressed in the DAC and its SLM and HLM 
configurations and by extension the potential for EU coordinated action. Discussions on aid effectiveness, prepared in the WP-EFF, allowed for 'give and take' and 'package deals' so that the EU could support the agenda as a whole: for instance, one member state less inclined to division of labour would nonetheless support the position as a whole due to the strong commitment to aid transparency. In contrast, discussions on ODA reporting as prepared in the WP-STAT directly affect individual donor interest, as a result of which they are often regarded in a 'zero sum' sense. ${ }^{17}$ WP-STAT reform proposals thus tend to be judged more on the basis of the effects these proposals would have on individual ODA budgets of members (i.e. would change $X$ represent an advantage for donor Y over Z?) and less on their developmental merits (Roodman, 2015). This approach naturally limits the possibility for coordinated action and affects discussions in the DAC: interviewees noted that different members tended to approach the discussion on the renewal of the DAC's mandate based on how it would serve them, as opposed to how it would serve the DAC. ${ }^{18}$

A third explanatory factor concerns the diverging preparatory processes among EU DAC members. The interview findings showed that DAC members differ considerably in terms of which ministries (and by extension areas of public policy) are involved in determining the member's views and positions on issues discussed in the DAC. One example mentioned was that in some members the ministry responsible for development policy enjoys considerable autonomy to engage in discussions on development finance, while in others detailed discussions with the finance ministry precede these. ${ }^{19}$ This means there is often considerable internal coordination within individual DAC members, which complicates a subsequent search for convergence and compromise. This was less the case for the EU institutions, where the DG for International Cooperation and Development (DEVCO) generally leads in preparing DAC discussions and may invite relevant other DGs to give inputs on particular topics, e.g. the EEAS when security-related topics are concerned (Prada, 2017). ${ }^{20}$ Interviewees maintained that DEVCO is responsible for 'heading IV' of the EU's which is largely reported as ODA, and the general impression is that the EEAS has not strongly asserted itself within the EU institutions as regards the engagement in the DAC. ${ }^{21}$

The particular relevance of the diverging preparatory processes for explaining Figure 1 is twofold. First, and linked to the political economy of EU development cooperation, the divergence among EU actors is greater in the ODA reporting case. The aid effectiveness case was essentially about defining and monitoring ambitious policy objectives, hence it was dealt with by the ministries of development in virtually all EU member states, whereas the ministry of finance is also involved in the ODA reporting case in several EU countries. Second, recent years have witnessed a lower ambition of overcoming the divergence within the EU. The EU's New Consensus on Development, for example, places strong emphasis on diversity and respective areas of comparative advantage, thus moving away from prior efforts to converge EU development practice and promote areas of specialisation where the EU would complement its member states (EU, 2017).

A fourth factor that explains the recent lack of EU coordination in the DAC relates to the mismatch between the DAC's decision-making culture and EU coordination mechanisms. As pointed out before, the DAC - and the OECD more generally - is an intergovernmental body in which decisions are taken by consensus. To get there, the DAC operates in a very deliberative way, striving to find the good common solutions for development problems, 
typically taking into account the research that has been carried out by the OECD's Development Cooperation Directorate on a particular topic as well as the input of its Member States. This is facilitated by the fact that the DAC itself is not involved in any operational activities, unlike most other IOs, making it an ideal forum for standard setting.

On any of the aforementioned contentious topics, in close consultation with the DAC Chair, the DCD can play a facilitating role, such as by initiating a meeting on a (sub)topic when it senses that the DAC members have not yet discussed it sufficiently. The Chair may also choose to convene meetings with or without the DCD's involvement. ${ }^{22}$ These meetings are crucial for DAC members to gain awareness of emerging positions and to broker compromises and consensus for formal meetings, where the two elected vice-chairs of the DAC tend to play an important role too. Interviews noted that crucial compromises in the DAC often emerge rather spontaneously from these various formal and informal meeting processes. ${ }^{23}$ Others noted strong differences between different chairs in terms of leadership styles as well as the way with which she/he worked with the secretariat. ${ }^{24}$ In view of these established as well as dynamic intra-DAC processes for facilitating consensus, it could be argued that there is limited scope and value for a separate EU-facilitated process to do something similar among $70 \%$ of the committee's membership.

While obviously certain Member States often can and do align on topics, they rarely present themselves as a 'bloc', whereas such practices are much more common and important in other IOs. From an EU coordination point of view, however, this decisionmaking style poses a number of challenges, knowing that the EU's institutional mechanism to achieve coordination are geared towards the decision-making culture of archetypical IOs - e.g. the UN, WTO or World Bank - which operate on the basis of coalition building, bloc formation and voting. For example, the provisions in the Lisbon Treaty that granted the EU legal personality, allowing the Union to enhance its membership status in IOs and potentially even speak on behalf of all EU Members have little practical relevance for the EU's involvement in the DAC as there is no culture of member speaking on behalf of larger groups. The legal obligation to 'coordinate their action in international organisations and at international conferences' (art 43(1)) thus has little practical relevance in the context of the DAC.

This being said, EU coordination does take place in the context of the regular DAC and DAC SLMs - the former at its EU Delegation and the latter at the OECD premises since many SLM participants from MS travel to Paris on the day itself. However, and in line with the previous paragraph, these only serve to inform each other about positions already taken and are not regarded upon as having potential in facilitating joint EU action and brokering of joint positions. Interviewees argued that the reason why these mechanisms are not used to align views and prepare joint EU positions was that some EU Member States consider that doing so would run counter to the DAC's decisionmaking culture. ${ }^{25}$ The EU itself argues that 'member states have always been reluctant to be coordinated [by the EU]' (Prada, 2017). The main exception to this role was in relation to the DAC's work on aid effectiveness (cf. Figure 1), where discussions took place in a dedicated working party with a larger and more diversified membership oriented towards preparing international HLFs on the topic, where the EU actively sought to pursue a single position to influence statements to be adopted at these fora. ${ }^{26}$ Importantly, this was perceived by the EU actors - but also the other DAC members - as 
appropriate behaviour, stemming from the specific nature of the HLFs and the preparatory processes leading up to these fora.

The fifth and final factor that explains the recent lack of EU coordination in the DAC concerns the EU's declining normative role in development cooperation. While in the period between 2005 and 2012 the EU took up an assertive normative role in the area of development policy, its normative distinction and engagement has declined in more recently. Rather than promoting its own normative position on development and seeking consensus among EU Member States, the EU has increasingly come to pursue its own interests in the work of the DAC. ${ }^{27}$ As a counterpoint, one interviewee suggested this had always been the case, but that the EU's own interests in development cooperation (e.g. its emphasis on budget support) simply had a better match with the aid effectiveness agenda during the WP-EFF period. ${ }^{28}$ This was particularly true in the context of the DAC's discussions on ODA reform, where the EU adopted positions which were first and foremost driven by its own interests and particular nature as a donor. Recent research (Verschaeve \& Orbie, 2015, 2017) shows that the EU has pro-actively engaged to gain acceptance as a quasi-bilateral donor in the DAC, in accordance with its full membership. In positioning itself as a donor and stressing it participates on the same level as states (Prada, 2017), the EU seeks to distinguish itself from multilateral organisations who also attend and engage in DAC debates.

During this discussion, the EU also decided to position the European Investment Bank (EIB) external lending mandate as ODA, and engaged in the so-called 'blending' of loans and grants, as well as additional cooperation measures to facilitate public and private investment. This reorienting cooperation profile encompassed a certain convergence towards France and Germany, who also avail over large shares of loans as part of their bilateral cooperation portfolios. ${ }^{29}$ Consequently, the EU's cooperation interests moved away from those member states who did not share many of these foci and interests. Moreover, in advocating the EIB loans the EU seemed more interested in the size of its own ODA-eligible contributions, and less in increasing the quality of ODA as per the ambition in the previous Consensus (EU, 2006). The discussion on the EIB loans put a strain on the relation between the EU and the OECD's Development Cooperation Directorate supporting the DAC's discussions (see Verschaeve \& Orbie, 2017). Beyond the DAC, there was increasing controversy around the latter group's use of 'profitable loans', in the sense that interest rates were so low that some donors were issuing loans when (assuming repayment) they would make a profit on their ODA (Roodman, 2015). Furthermore, on several topics - most notably the issue of concessional loans - the DAC struggled for several years, leading to some observers openly questioning the Committee's ability to deal with the monitoring of aid flows (Verschaeve \& Orbie, 2017).

In earlier years, the EU sought to promote policy convergence around several aspects of aid effectiveness, such as new aid modalities and aid untying (Carbone, 2014). Several interviewees noted that whereas the EU was previously strongly engaged in promoting effective development cooperation, including by adopting specific EU ambitions that went beyond the level of ambition agreed in the Paris Declaration (EU, 2006), its current positions seemed to mainly serve its own interests as a donor and global actor more generally. ${ }^{30}$ When this concerned aspect such as the concessionality discussion where the EU's position was not unambiguously seen as 'developmental', this was seen to negatively affect the EU's legitimacy as a member of the DAC (Verschaeve \& Orbie, 2017). ${ }^{31}$ 


\section{Conclusion}

In recent years, the EU has increased its ambition to promote a common European vision on development and facilitate EU collective action to pursue this vision. This is also clearly reflected in the newly adopted European Consensus on Development (2017), pointing out that the 'EU and its Member States must be united in diversity, using a variety of experiences and approaches, bearing in mind their respective comparative advantage' (EU, 2017). Therefore, the main objective of this article was to analyse EU dynamics within the OECD-DAC, wondering whether and to what extent the EU and its Member States make efforts to work together in Paris. In doing so, this study focused on the period between 2003 and 2017, analysing two cases that both dominated the work of the DAC during specific intervals of this period, namely, (i) aid and development effectiveness and (ii) ODA reform.

The review of primary and secondary documents as well as the analysis of interview findings pointed to a process in which the EU and its member states' cooperation policies and operations began to diverge over the span of a number of years, notably after the start of the 2008 financial and economic crisis that encompassed the waning of the international aid effectiveness agenda. Indeed, the situation was such that although the EU was legally more empowered to take joint action in the DAC, the substance of the discussions in the DAC had evolved in a way that made this less likely. The WP-EFF period (20032012) also coincided with the European Commission taking up a more assertive normative role in the area of development policy, which both informed and accompanied the EU enlargement process which consequently enlarged the Commission's ODA budget. In the years following the entering into force of the Lisbon Treaty, the EU's normative role in development policy paradoxically declined - with exception of its role in representing Union-wide positions in the post-2015 negotiations - while the EU focused more strongly on its own ODA implementation roles while de-emphasising its role in promoting European integration in development policy.

A key implication for further theoretical and empirical research is to what extent the own institutional interests of the EU create trade-offs with its supranational roles and responsibilities as assigned by the Treaties. This article's findings reflect a decreasing alignment of the international development policy agenda with the EU's development cooperation approaches, and show that the EU's increased ambition in terms of volume and implementation approaches prevents it from seeking compromises with EU member states that operate with very different systems. Moreover, the findings confirm our expectation that the EU has to meet different expectations as the only non-state full member of the DAC. This can be linked to the predominantly historical as opposed to functional justification for its full membership, but it may also be assumed that IO-participation (as 'public good' promoting entities) are expected to lead by example in promoting the IO's stated mandate and objectives. Based on these findings, we expect that further research could further explore and interrogate these findings non-state member engagement in IOs as well as develop typologies of 'membership types' as per members' specific modes of engagement.

\section{Notes}

1. Throughout the article, unless indicated otherwise, the term EU is used to refer to the European Commission as the dominant EU institution in development policy. 
2. Curiously, the OECD's own leadership showed similar tendencies, with past Secretaries General considering that it is becoming increasingly difficult to describe what it is, as well as acknowledging that they experience difficulty in communicating what it does (Marcussen \& Trondal, 2011).

3. Interviewees were selected from the personal networks of both authors and complemented with the snowball sampling technique. This approach was possible due to the fact that both authors conducted previous research on this topic.

4. These for instance concerned DAC meetings observed by one of the authors, as well as a recent of views in the European Parliament with the European Commission regarding the latter's role in the DAC (Prada, 2017).

5. The European External Action Service appended its signature of the Consensus in 2014.

6. Source: http://www.oecd.org/about/membersandpartners/\#d.en.194378.

7. The exception concerns the election of representatives, such as the vice-chairs of the DAC (interview 12).

8. At the time this paper was written, the DAC consisted of 30 members, including the European Union as a full member (source: http://www.oecd.org/dac/dacmembers.htm).

9. One example was that the large subsidiary body of the Working Party on Aid Effectiveness was set up by the DAC, without the involvement of the OECD Council. (pers. communication).

10. Interview 14.

11. Interviews $2,9,12$.

12. Interview 11.

13. Interviews $1,3,4,7,9,10,11$.

14. Interviews 5, 11.

15. Interview 6.

16. Interview 11.

17. Interviews 4, 8, 14 .

18. Interviews $6,15$.

19. Interviews 4, 7 .

20. Interviews 2, 15.

21. Interviews $2,11$.

22. Interviews 1, 3, 9, 14.

23. Interview 13.

24. Interviews 5, 8, 12, 13, 14.

25. Interviews 3, 11.

26. Interview 8, 11.

27. Interviews $1,7,9,10,12,13$.

28. Interview 5.

29. Interviews 4, 5 .

30. Interviews 1, 3, 7, 9, 10, 12.

31. Interview 13.

\section{Acknowledgements}

Earlier versions of this article were presented and discussed at a workshop on the 'DAC and Development Co-Operation' at the Centre for Global Cooperation Research in Duisburg (May 2017) and at the 24th International Conference of Europeanists in Glasgow (July 2017). The authors also gratefully acknowledge the feedback from the two anonymous reviewers. Responsibility is the authors'.

\section{Disclosure statement}

No potential conflict of interest was reported by the authors. 


\section{Notes on contributor}

Niels Keijzer is a researcher based at the German Development Institute / Deutsches Institut für Entwicklungspolitik (DIE), Bonn, Germany. His research and advisory work focuses on European development cooperation, external evaluations, aid and development effectiveness, policy coherence for development and financing for development.

Joren Verschaeve is an assistant-professor at the Centre for EU Studies of Ghent University, Belgium. His main interests, expertise and teaching experience covers the area of EU external policy, with a particular emphasis on EU development policies and the relationship between the EU and international institutions, and the OECD/DAC specifically.

\section{References}

Abbott, K. W., \& Snidal, D. (1998). Why states act through formal international organizations. Journal of Conflict Resolution, 42(1), 3-32.

Ad Hoc Working Party on Harmonisation (Ad-hoc WG). (2004). Report of the Ad Hoc Working Party on Harmonisation - advancing coordination, harmonisation and alignment: The contribution of the EU (Council Doc 14670/04). Retrieved from http://register.consilium.europa.eu/doc/srv?l=EN\&f= ST2014670202004\%20INIT

Ashoff, G. (2013). 50 years of peer reviews by the OECD's development assistance committee (Briefing Paper 2/2013). Bonn: German Development Institute / Deutsches Institut für Entwicklungspolitik (DIE).

Carbone, M. (2007). The European Union in international development. London: Routledge.

Carbone, M. (2013). Between EU actorness and aid effectiveness: The logics of EU aid to Sub-Saharan Africa. International Relations, 27(3), 341-355.

Carbone, M. (2014). Much ado about nothing? The European Union and the global politics of untying aid. Contemporary Politics, 20(1), 103-117.

Carbone, M., \& Keijzer, N. (2016). The European Union and policy coherence for development: Reforms, results, resistance. The European Journal of Development Research, 28(1), 30-43.

Carroll, P., \& Kellow, A. (2011). The OECD. A study of organisational adaptation. Cheltenham: Edward Elgar.

Debaere, P., De Ville, F., Orbie, J., Saenen, B., \& Verschaeve, J. (2016). Membership: The evolution of EU membership in major international organisations. In A. Orsini (Ed.), The European Union with(in) international organisations (pp. 35-55). London: Routledge.

Delputte, S., \& Orbie, J. (2014). The EU and donor coordination on the ground: Perspectives from Tanzania and Zambia. The European Journal of Development Research, 26(5), 676-691.

Delputte, S., Orbie, J., Lannoo, S., \& Verschaeve, J. (2016). Europeanisation of aid budgets: Nothing is as it seems. European Politics and Society, 17(1), 74-89.

De Milly, H. (2012). From aid effectiveness to development effectiveness: Paying tribute to the WP-EFF. Retrieved from http://www.hiidunia.com/wp-content/uploads/downloads/2012/06/120614Celebrating-Busan.pdf

Dijkstra, H. (2017). Collusion in international organisations: How states benefit from the authority of secretariats. Global Governance, 23(4), 601-618.

EU. (2006). The European consensus on development. Retrieved from https://ec.europa.eu/europeaid/ sites/devco/files/publication-the-european-consensus-on-development-200606_en.pdf

EU. (2017). The new European consensus on development, "our world, our dignity, our future". Brussels. Retrieved from http://www.consilium.europa.eu/en/press/press-releases/2017/05/pdf/Europeanconsensus-on-development/

European Council (EC). (2001). Göteborg European council 15-16/06/2001. Presidency conclusions and annexes. Retrieved from http://aei.pitt.edu/43342/

European Council (EC). (2017). EU official development assistance reaches highest level ever, European commission - press release. Brussels. Retrieved from http://europa.eu/rapid/press-release_IP-17916_en.htm 
Farrell, M. (2012). The EU and UN development policy. In S. Gänzle, S. Grimm, \& D. Makhan (Eds.), The European Union and global development: An 'enlightened superpower in the making? (pp. 229-245). Hampshire: Palgrave.

Faust, J., \& Messner, D. (2007). Organizational challenges for an effective aid architecture - traditional deficits, the Paris agenda and beyond (Discussion Paper 20/2007). Bonn: German Development Institute (DIE).

Gavas, M., \& Maxwell, S. (2017). Walking on two legs: Culture and calculus in European Union development cooperation. Development Policy Review, 35(4), 587-597.

Griffiths, R. (1997). Explorations in OEEC history. Paris: OECD.

Grilli, E. (1993). The European community and the developing countries. Cambridge: Cambridge University Press.

Hadzhieva, E. (2015). The European Union's role in international economic fora - paper 3: The OECD. Study commissioned by the EP. Brussels: EP.

Hofferberth, M., Brühl, T., Burkart, E., Fey, M., \& Peltner, A. (2011). Multinational enterprises as "social actors"-constructivist explanations for corporate social responsibility. Global Society, 25(2), 205-226.

Hoffmeister, E. (2007). Outsider or frontrunner? Recent developments under international and European law on the status of the European Union in international organizations and treaty bodies. Common Market Law Review, 44(1), 41-68.

Holden, P. (2014). Tensions in the discourse and practice of the European Union's aid for trade. Contemporary Politics, 20(1), 90-102.

Holland, M., \& Doidge, M. (2012). Development policy of the European Union. Basingstoke: Palgrave Macmillan.

Jørgensen, K. E. (2009). The European Union and international organizations. London: Routledge.

Kaddous, C. (Ed.). (2015). The European Union in international organisations and global governance: Recent developments. Oxford: Hart.

Koch, S., \& Molenaers, N. (2016). The Europeanisation of budget support: Do government capacity and autonomy matter? European Politics and Society, 17(1), 90-104.

Lightfoot, S., \& Kim, S. (2017). The EU and the negotiation of global development norms: The case of aid effectiveness. European Foreign Affairs Review, 22(2), 159-175.

Lightfoot, S., \& Szent-Iványi, B. (2014). Reluctant donors? The Europeanization of international development policies in the new member states. JCMS: Journal of Common Market Studies, 52(6), $1257-1272$.

Marcussen, M., \& Trondal, J. (2011). The OECD civil servant: Caught between Scylla and Charybdis. Review of International Political Economy, 18(5), 592-621.

Moravcsik, A. (1993). Preferences and power in the European community: A liberal intergovernmentalist approach. JCMS: Journal of Common Market Studies, 31(4), 473-524.

OECD. (1960). Convention on the organisation for economic co-operation and development. Retrieved from http://www.oecd.org/general/conventionontheorganisationforeconomicco-operationandde velopment.htm

Orbie, J., \& Lightfoot, S. (2017). Development: Shallow Europeanisation? In A. Hadfield, I. Manners, \& R. G. Whitman (Eds.), Foreign policies of EU member states. Continuity and Europeanisation (pp. 201217). London: Routledge.

Orsini, A. (Ed.). (2016). The European Union with(in) international organisations: Commitment, consistency and effects across time. London: Routledge.

Prada, G. M. (2017). Remarks on behalf of DG DEVCO at exchange of views with the European parliament on the commission's role in the DAC (notes taken by authors' based on the online recording of the meeting). Retrieved from http://www.europarl.europa.eu/ep-live/en/committees/video? event=20170626-1500-COMMITTEE-DEVE

Roodman, D. (2015). On measuring loan concessionality in official development assistance. Oxford Review of Economic Policy, 31(3-4), 396-419.

Schilz, J. (2005). Speech by Jean-Louis Schiltz at the high level forum on aid effectiveness. Retrieved from http://www.eu2005.lu/en/actualites/discours/2005/03/0102schiltz/index.html 
Scott, S. (2015). The accidental birth of "official development assistance" (OECD development co-operation Working Paper 24). Paris: OECD.

Scott, S., \& Ahmad, Y. (2011). Measuring aid. 50 years of DAC statistics, 1961-2011. Paris: OECD.

Verschaeve, J., \& Orbie, J. (2016). Once a member, always a member? Assessing the importance of time in the relationship between the European Union and the development assistance committee. Cambridge Review of International Affairs, 29(2), 512-527.

Verschaeve, J., \& Orbie, J. (2017). Ignoring the elephant in the room? Assessing the impact of the European Union on the development assistance committee's role in international development. Development Policy Review. doi:10.1111/dpr.12216

Verschaeve, J., \& Takacs, T. (2013). The EU's international indentity: The curious case of the OECD. In H. Dewaele \& J. J. Kuipers (Eds.), The emergence of the European Union's international identity. Views from the global arena (pp. 187-209). Leiden: Martinus Nijhoff.

Woodward, R. (2009). The organisation for economic cooperation and development. London: Routledge.

\section{Interviews}

Interview 1: MS official, headquarters, January 2017.

Interview 2: two EU officials, headquarters, March 2017.

Interview 3: MS official, headquarters, March 2017.

Interview 4: Two MS officials, headquarters, March 2017.

Interview 5: MS official, headquarters, April 2017.

Interview 6: MS official, Paris-based, April 2017.

Interview 7: Four OECD officials, Paris-based, April 2017.

Interview 8: MS official, Paris-based, April 2017.

Interview 9: EU official, Paris-based, April 2017.

Interview 10: CSO official, Paris-based, April 2017.

Interview 11: DAC member (non-EU member), headquarters, May 2017 (telephone).

Interview 12: MS official, headquarters, May 2017 (telephone).

Interview 13: DCD official, May 2017 (telephone).

Interview 14: DCD official, June 2017 (telephone).

Interview 15: EU official, headquarters, July 2017. 